\title{
Aerodynamic Analyses and Database Development for Ares I Vehicle First Stage Separation
}

\author{
Bandu N. Pamadi ${ }^{1}$ \\ NASA Langley Research Center, Hampton, VA 23681 \\ Jing $\mathrm{Pei}^{2}$ \\ NASA Langley Research Center, Hampton, VA 23681 \\ Jeremy T. Pinier ${ }^{3}$ \\ NASA Langley Research Center, Hampton, VA 23681 \\ Goetz H. Klopfer ${ }^{4}$ \\ NASA Ames Research Center, Moffett Field, CA 94035 \\ Scott D. Holland ${ }^{5}$ \\ NASA Langley Research Center, Hampton, VA 23681 \\ Peter F. Covell ${ }^{6}$ \\ NASA Langley Research Center, Hampton, VA 23681
}

This paper presents the aerodynamic analysis and database development for first stage separation of Ares I A106 crew launch vehicle configuration. Separate 6-DOF databases were created for the first stage and upper stage and each database consists of three components: (a) isolated or freestream coefficients, (b) power-off proximity increments, and (c) power-on proximity increments. The isolated and power-off incremental databases were developed using data from 1\% scaled model tests in AEDC VKF Tunnel A. The power-on proximity increments were developed using OVERFLOW CFD solutions. The database also includes incremental coefficients for one BDM and one USM failure scenarios.

\section{Nomenclature}

$\mathrm{C}_{\mathrm{A}} \quad=$ axial force coefficient, axial force/qSD

$\Delta \mathrm{C}_{\mathrm{A}} \quad=$ incremental axial force coefficient

$\mathrm{C}_{1} \quad=$ rolling moment coefficient, rolling moment/qSD

$\Delta \mathrm{C}_{1} \quad=$ incremental rolling moement coefficient

$\mathrm{C}_{\mathrm{m}} \quad=$ pitching moment coefficient, pitching moment/qSD

\footnotetext{
${ }^{1}$ Ares I Aero Database Manager, Langley Ares Project Office, Senior Aerospace Engineer, Vehicle Analysis Branch, Systems Analysis and Concepts Directorate, Associate Fellow AIAA, Bandu.N.Pamadi@nasa.gov

${ }^{2}$ Aerospace Engineer, Vehicle Analysis Branch, Systems Analysis and Concepts Directorate, member AIAA, Jing.Pei-1@nasa.gov

${ }^{3}$ Aerospace Engineer, Configuration Aerodynamics Branch, Senior Member AIAA, Jeremy.T.Pinier@nasa.gov

${ }^{4}$ Senior Aerospace Engineer, Modeling and Simulation Application Branch, NASA Advance Supercomputing

Division, Exploration Systems Mission Directorate, Goetz.H.Klopfer@nasa.gov

${ }^{5}$ Vehicle Integration Element Manager, Langley Ares Project Office, Senior Aerospace Engineer, Aerothermodynamics Branch, Associate Fellow AIAA, $\underline{\text { Scott.D.Holland@nasa.gov }}$

${ }^{6}$ Chief Engineer, Langley Ares Project Office, Senior Aerospace Engineer, Vehicle Analysis Branch, Systems Analysis and Concepts Directorate, Associate Fellow, AIAA, Peter.F.Covell@nasa.gov.
} 


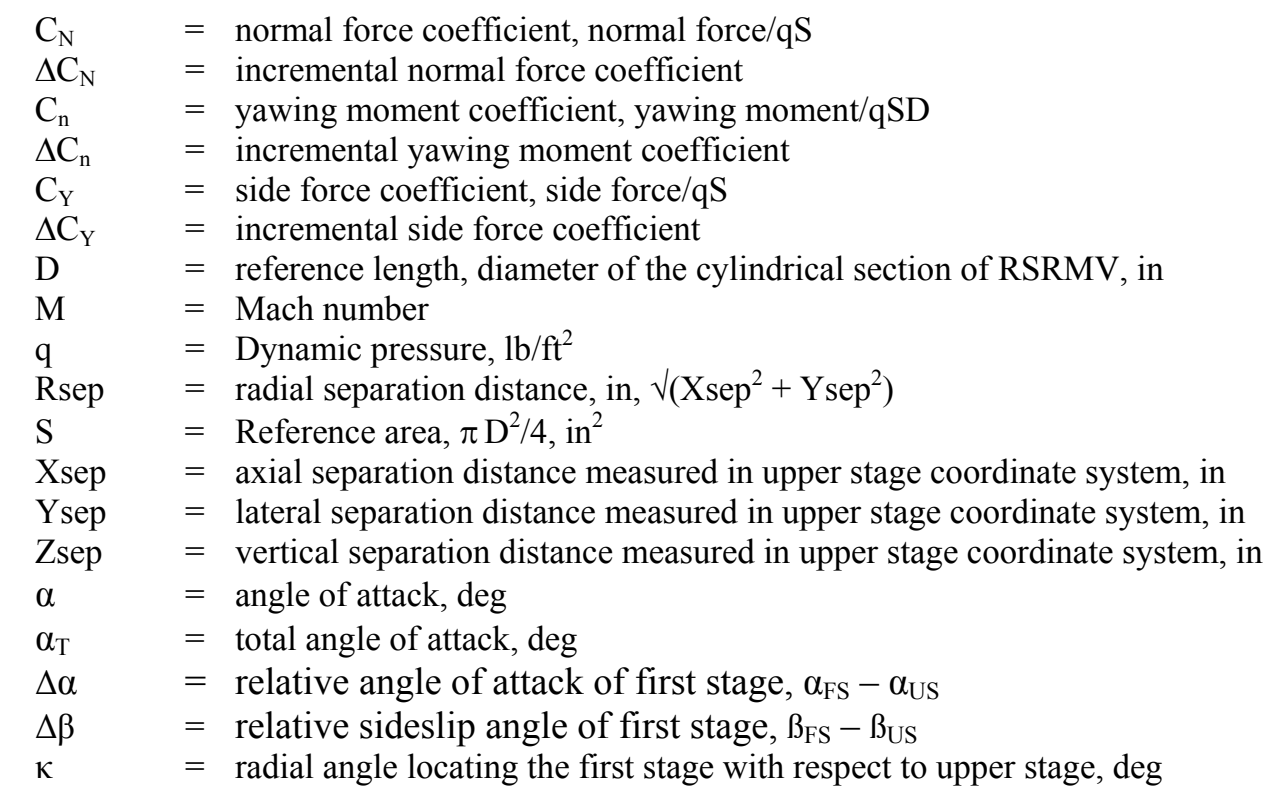

Acronyms:

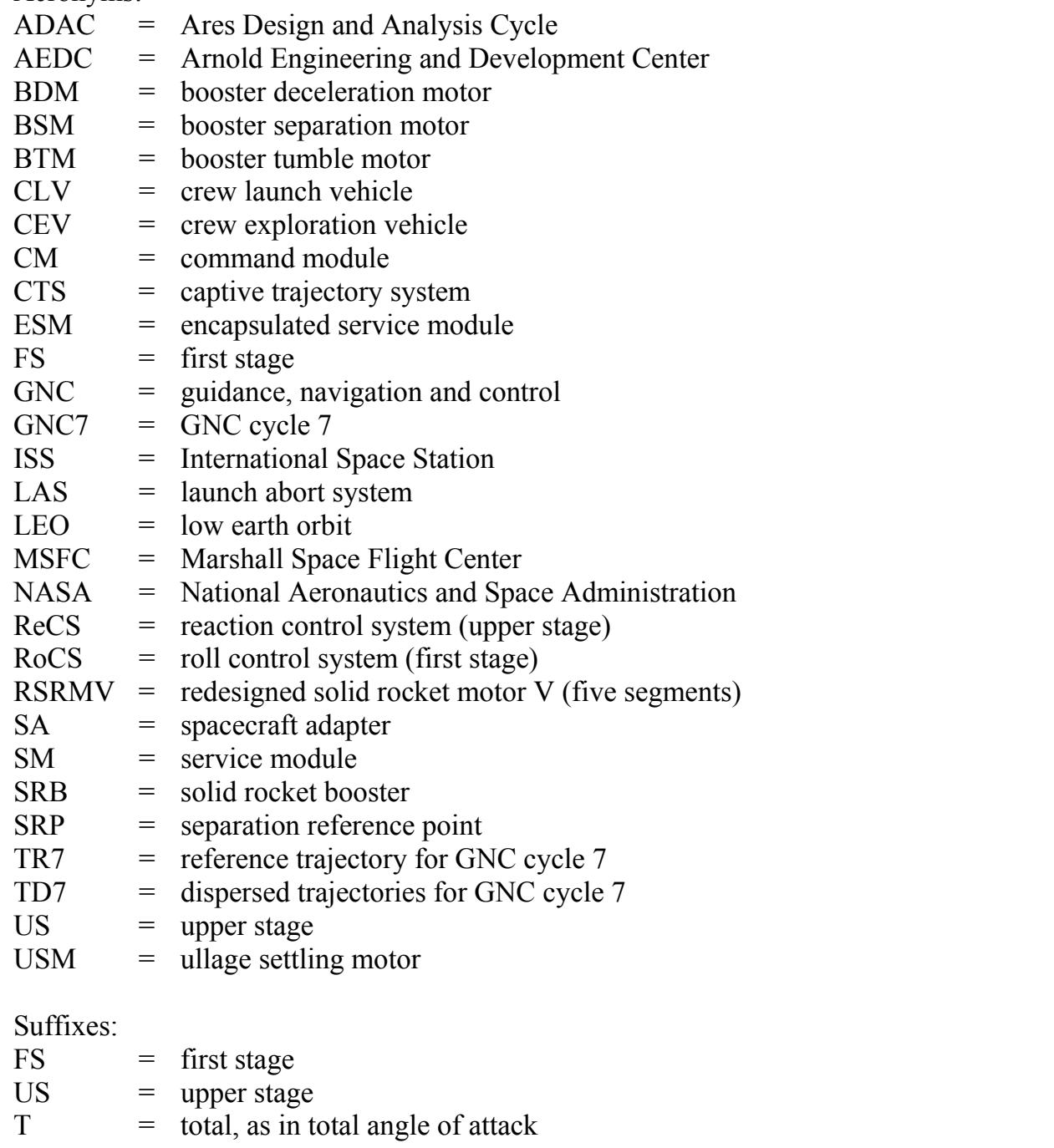




\section{Introduction}

The Constellation program was a key element of NASA's Vision for Space Exploration. ${ }^{1}$ One of the primary elements of that program was the design and development of a crew launch vehicle (CLV) to launch the crew exploration vehicle (CEV) into Low Earth Orbit (LEO). The CLV as later named the Ares I. The Ares design and analyses cycle (ADAC) began in 2006 and the Ares I vehicle configuration gradually evolved with progression of ADAC activity. The preliminary design review of the Ares I was held in September 2008, the critical design review was scheduled for 2011 and Ares I was expected to be operational by 2015. The first developmental test vehicle named Ares I-X was flown successfully on October 28, 2009. However, the constellation program was canceled in October 2010. At that time, the ADAC-3 was in progress and the vehicle configuration was designated as A106. NASA Langley Research Center in partnership with NASA MSFC and NASA Ames Research Center was involved in aerodynamic characterization and database development activity for A106 configuration. Ref. 2 discusses the development of lift-off/transition and ascent databases for the A106 configuration. This paper discusses the development of the database for A106 first stage separation.

The Ares I is a multistage launch vehicle (Figure 1). The first stage is a five-segment redesigned solid rocket motor (RSRMV), a derivative of the Space Shuttle four-segment solid rocket booster and is being developed by ATK under contract with NASA. The second stage vehicle comprises the launch abort system (LAS), the crew module $(\mathrm{CM})$, the service module (SM), the spacecraft adapter (SA), the upper stage propulsion elements such as liquid oxygen (LOX) and hydrogen (H2) tanks; and the J2-X engine. The combination of the LAS, the CM, the SM and the $\mathrm{SA}$, is called the crew exploration vehicle (CEV), which is also known as Orion.

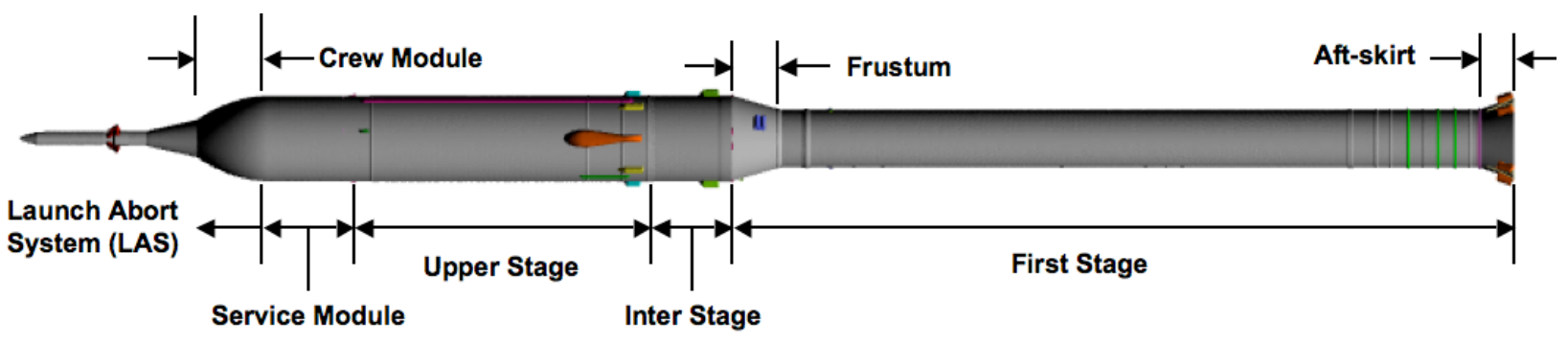

Figure 1. Sketch of Ares I A106 vehicle showing major components of launch configuration.

The A106 configuration has 10 booster deceleration motors (BDMs) located on the aft-skirt of the first stage and 4 booster tumble motors (BTMs) contained in 2 pods ( 2 motors in each pod) on the frustum. Each BDM is the same as the Space Shuttle booster separation motor (BSM) used for SRB separation from the External Tank/Orbiter. The BDMs are used to decelerate the first stage relative to the upper stage to aid axial separation. When the two stages are separated safely, the BTMs fire to put the first stage (with interstage attached) in a tumbling motion to dissipate energy and aid the parachute recovery. The first stage roll control system (RoCS) motors are located on the interstage and are used to balance the first stage combined aerodynamic rolling moment and the induced roll torque due to swirl and asymmetrical burning of the RSRMV. The upper stage reaction control motors (ReCS) are used for upper stage roll control subsequent to stage separation. All of the external structures, except the LAS nozzles, are usually referred to as protuberances. The umbilical between the CM and the SM, and the LH2 feed-line fairing are two of the prominent protuberances on the A106 configuration. The major components and protuberances of the A106 configuration are shown in Figure 1.

The nominal ascent trajectory (TR7 from GNC cycle 7) for the international space station (ISS) mission is shown in Figure 2. After lift-off/transition, the vehicle makes a gravity turn and follows a non-lifting ascent trajectory up to staging which nominally occurs around Mach 5.7 and an altitude of about 190,000 ft. However, in dispersed TD7 (GNC cycle 7) simulations, the staging was found to occur anywhere from Mach 5 to 6 and altitudes from 180,000 ft to $195,000 \mathrm{ft}$. The dynamic pressure ranges from $10 \mathrm{psf}$ to $40 \mathrm{psf}$ and the aerodynamic forces/moments during separation are small but not negligible. The first stage recovery process is similar to that of the current Shuttle SRB. The LAS separation occurs at approximately at Mach 6.5 at an altitude of 200,000 ft. Subsequently, the CEV separates from the upper stage (without LAS) and continues its journey to the ISS. The rest of the upper stage disintegrates during its return to Earth and it is not recovered.

The staging process is an in-line separation of the first stage from the upper stage exposing the J2-X engine and is possibly the most critical part of the Ares I CLV flight for a successful mission. Apollo/Saturn launch vehicles also had an in-line first stage separation (Ref. 3). At staging, the thrust of the first stage booster will be a small frac- 


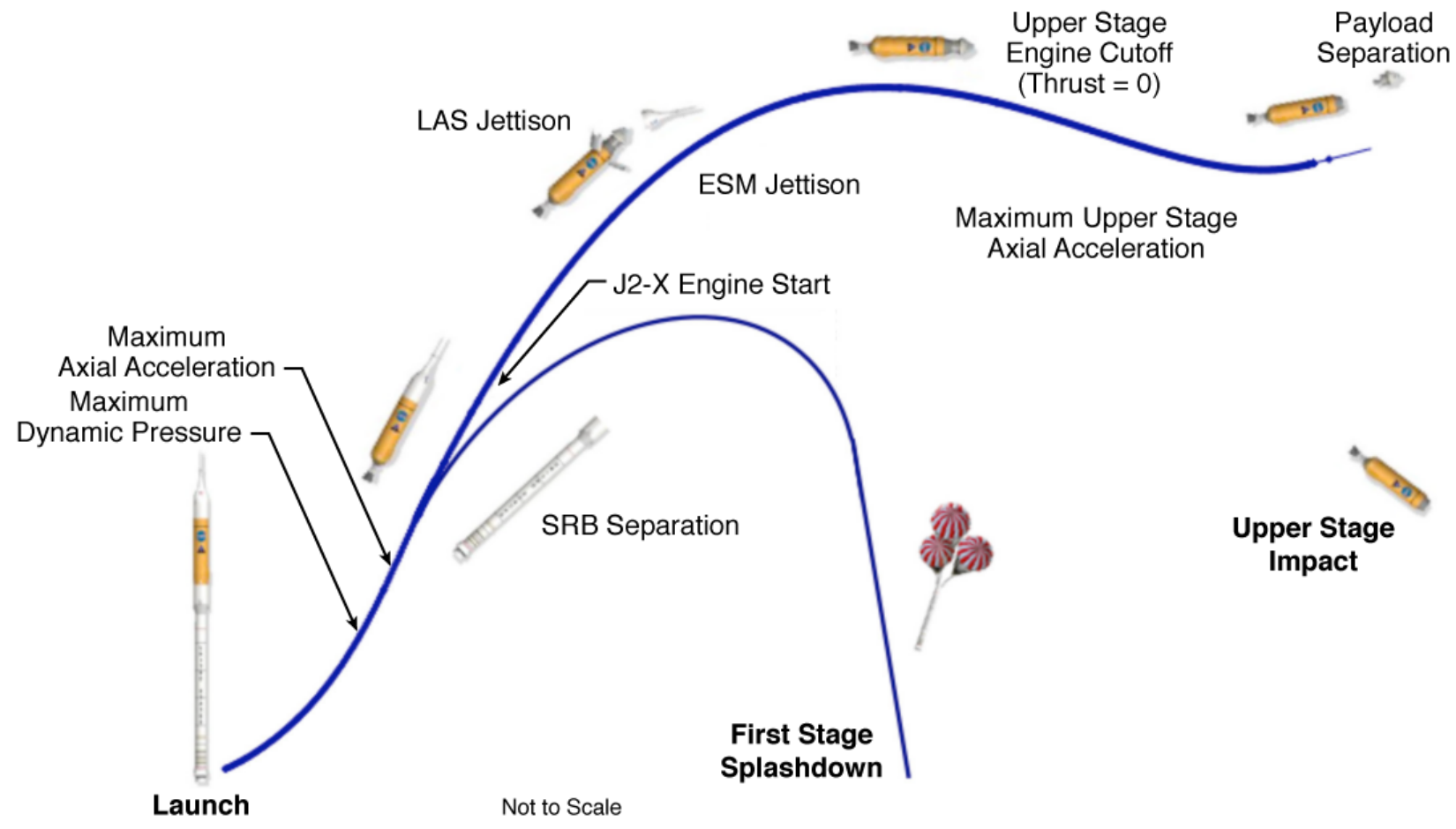

Figure 2. Ares I A106 crew launch vehicle nominal ascent trajectory.

tion of its initial value at lift-off and tails off to zero gradually. The start of separation is marked by the severance of the joint that connects the upper and the first stage. At that time, the 4 Ullage Settling Motors (USMs) on the upper stage and the 10 Booster Deceleration Motors (BDMs) on the first stage will have reached their full nominal thrust values. The J2-X engine thrust is very small until the first stage clears the J2-X nozzle. The stage separation is assumed to be complete after $2.5 \mathrm{sec}$ when the axial separation between the two stages is about 4 RSRMV diameters. At this point, the tumble motors fire initiating first stage tumble and subsequent recovery. The Ares I System Requirements Document ${ }^{4}$ states that the Ares I shall provide flight separations without recontact with any flight hardware required to complete the planned mission.

The proximity aerodynamics is complex and challenging due to presence of USM, BDM and J2-X plumes causing complex flow interactions in the upper stage base area and the first stage open cup region. It is equally challenging to design and fabricate small test models (typically $1 \%$ scale) simulating all the plumes and obtain reliable test data for database development. The modern CFD capability that was not available during Apollo/Saturn and Space Shuttle development era is a viable option but it is difficult to validate CFD results in the absence of suitable test data.

The analysis and database discussed in this paper covers the separation event from start (mated condition) until the tumble motors fire. This database was developed to support GNC8 (GNC cycle 8). It consists of two parts, one for the first stage and the other for the upper stage. Each part consists three components: (i) isolated freestream coefficients, (ii) power-off proximity increment coefficients, and (iii) power-on proximity increments when all plumes are firing at their nominal thrust values. To meet Ares program requirements, the database also has two additional components, power-on proximity increments for $1 \mathrm{BDM}$ out and one USM out when all the rest of the motors fire nominally. The 1 BDM out and 1 USM out incremental databases were developed for different individual BDM and USM failure scenarios.

The isolated freestream and power-off incremental database were developed using data from $1 \%$ scaled model stage separation tests in AEDC Von Karman Facility (VKF) Tunnel A at Mach 5.5. All power-on proximity increments including the one BDM out and one USM out cases were estimated using OVERFLOW CFD solutions. The development of uncertainty is not discussed in this paper. Conducting power-on stage separation tests was outside the scope of this activity. 


\section{Stage Separation Variables}

During separation, the location of the first stage (FS) with respect to the upper stage (US) is defined through the separation reference point (SRP). The SRP is defined as the midpoint on the centerline of the fuselage station of the parting plane at separation. $\mathrm{SRP}_{\mathrm{FS}}$ denotes the center of the separation plane on the FS, and $\mathrm{SRP}_{\mathrm{US}}$ denotes the center of the separation plane on the US. By definition, $\mathrm{SRP}_{\mathrm{FS}}$ and $\mathrm{SRP}_{\mathrm{US}}$ are coincident prior to separation. Translational separation is defined as the location of $\mathrm{SRP}_{\mathrm{FS}}$ relative to $\mathrm{SRP}_{\mathrm{US}}$ in the upper stage coordinate system. The axial, lateral, and vertical displacements are defined as Xsep, Ysep and Zsep respectively. The angular orientation of the first stage with respect to the upper stage is defined by the relative angle of attack $(\Delta \alpha$ and sideslip angle $(\Delta \beta$. Figure 3 illustrates the nomenclature and the moment reference points used in the stage separation database. The upper stage moment reference center is located at the mid point of the separation plane and the first stage moment reference center is located at the gimbal point.

\section{Wind Tunnel Tests}

The power-off stage separation tests
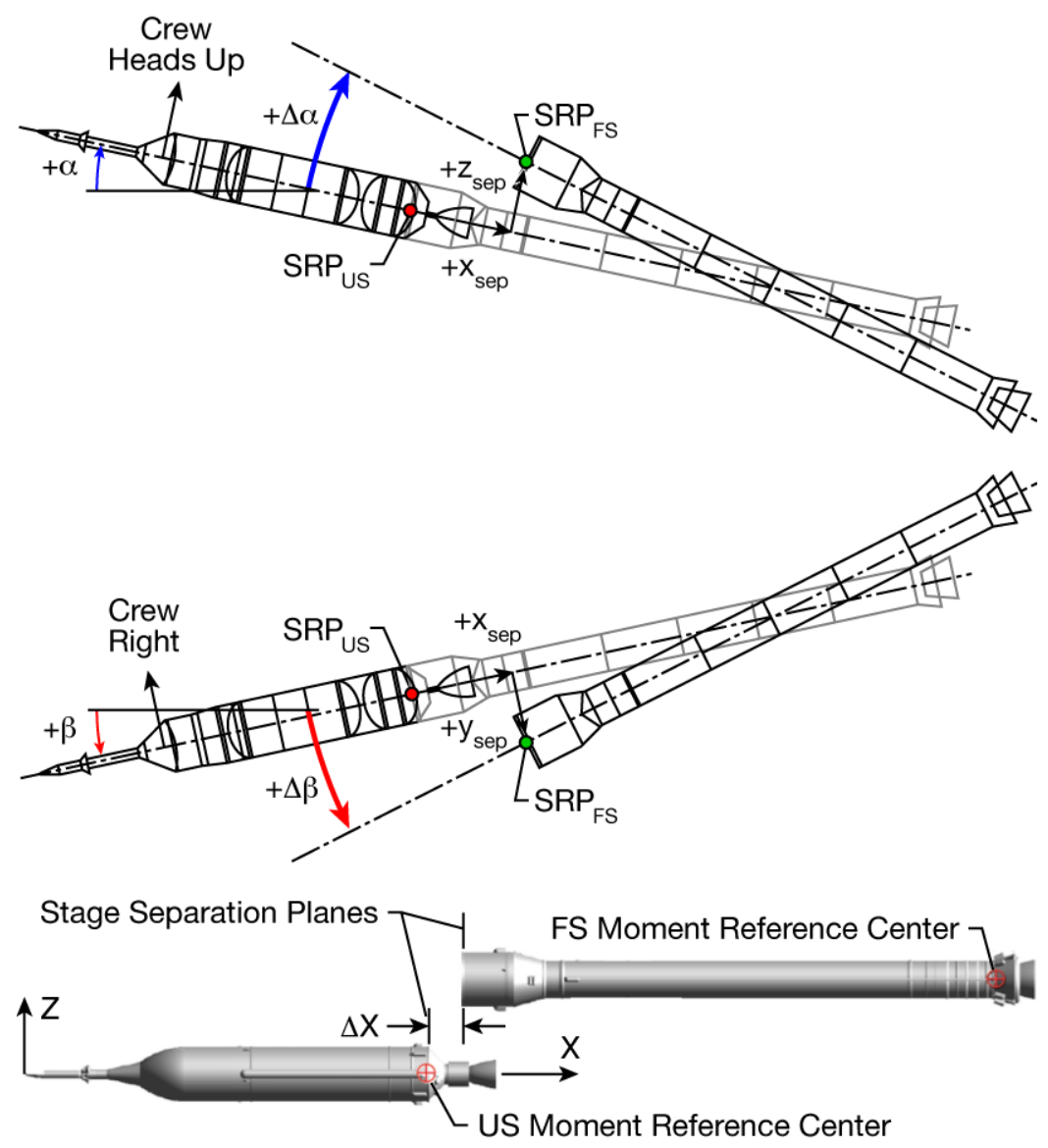

Figure 3. Stage separation nomenclature.

were conducted at AEDC Von Karman Facility Tunnel A (VKF-A) during July 2008. At that time, the current Ares configuration was A103. The AEDC test was designated as Test VA-482 and was conducted on 1\% A103 scale model at Mach 5.5 using the captive trajectory system (CTS). The CTS rig permitted positioning the first stage relative to the upper stage for all required combinations of translational and rotational orientations.

The database was developed using test data on clean axially symmetric models (no protuberances). However, the upper stage model is not perfectly axially symmetrical because it includes the Launch Abort System (LAS). The isolated (freestream) database was developed using test data on first stage and upper stage in isolation and the power-off proximity incremental database was developed using data from tests conducted with both stages in close proximity. Some limited test data were acquired on A103 test models with protuberances and these data were used to estimate uncertainty.

Figure 4 illustrates the test setup. The upper stage was blade mounted which allowed it to be pitched in the vertical plane. The first stage was sting mounted which allowed both translational and rotational motion relative to the upper stage.

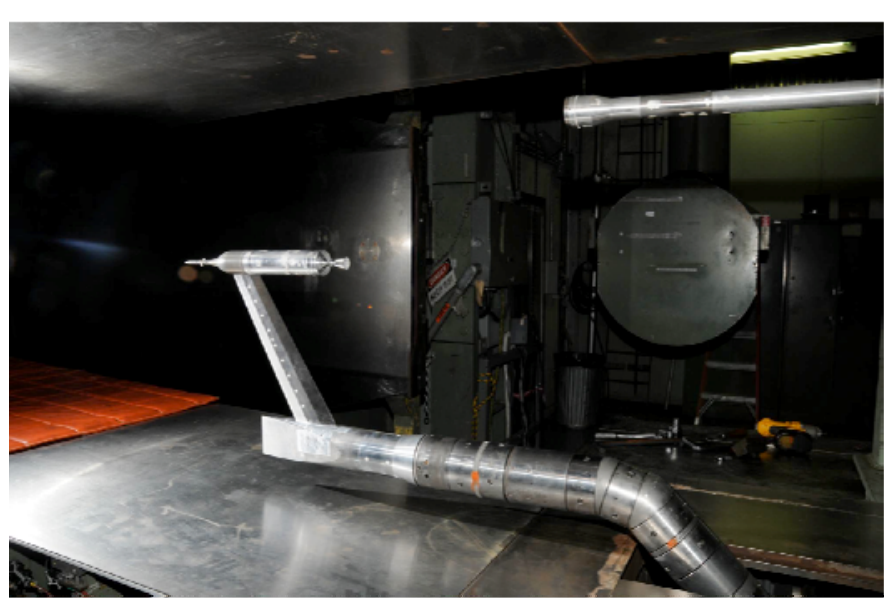

Figure 4. Test model in AEDC VKF Tunnel A. 
Figure 5 illustrates the nozzle position relative to the cup when the first stage is at a $\Delta \alpha$ and Xsep.

The power-off test matrix was developed to cover the dispersed TD6 separation trajectories because that was the current information when AEDC tests were conducted in July 2008. The test matrix had to be developed in advance because CTS system needs to be pre-programmed before the commencement of each test. In view of this, it was necessary to ensure that no physical contact occurred between the first stage and upper stage models at any location in the test matrix particularly when the two models were in very close proximity. A special collision detection code in MATLAB was developed to determine the closest possible locations without collision. The total air-on occupancy hours for Ares I stage separation tests in AEDC VKF Tunnel A were about 130.

In AEDC tests, the lateral location of the FS with respect to US was identified by radial (Rsep) and angular (kappa ' $\kappa$ ') location rather than Ysep and Zsep as shown in Figure 6. There are six independent variables in the power-off AEDC stage separation test data is given in Table I. During the tests, the upper stage remained stationary at a given angle of attack. The first stage was set to the desired $\Delta \alpha, \Delta \beta$, Rsep and $\kappa$. Then, the CTS rig traversed it to all the pre-programmed axial (Xsep) locations in the test matrix for that combination of test variables.

Table I. Range of variables for power-off stage separation tests

\begin{tabular}{cccccc}
\hline \hline $\begin{array}{c}\alpha_{\text {T,US }}, \\
\text { deg }\end{array}$ & $\begin{array}{c}\Delta \alpha, \\
\text { deg }\end{array}$ & $\begin{array}{c}\Delta \beta, \\
\text { deg }\end{array}$ & Xsep/D & Rsep/D & $\kappa$ \\
\hline $\mathbf{0 , 5 , 1 0}$ & $-\mathbf{5 , 0 , 5}$ & $-\mathbf{5 , 0 , 5}$ & $\begin{array}{c}\mathbf{0 . 1} \text { to } \\
\mathbf{0} \text { to }\end{array}$ & $\mathbf{0}$ to \\
\hline \hline
\end{tabular}
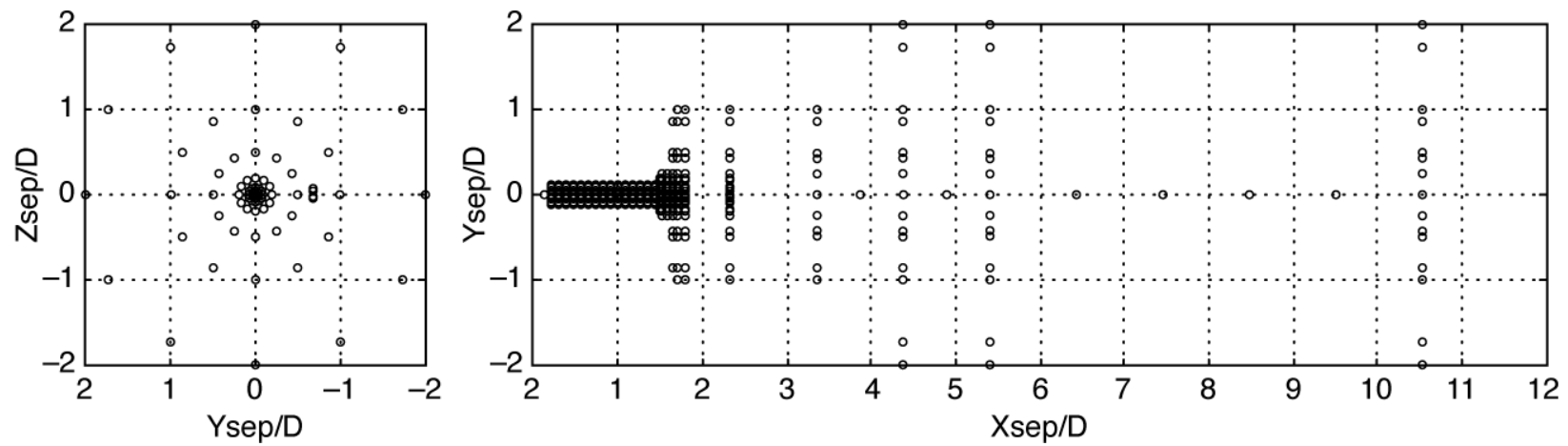

Figure 7. Schematic illustration of AEDC test matrix for upper stage angles of attack of 0 and $5 \mathrm{deg}$.

The majority of the test data were taken at small Xsep/D and Rsep/D locations where the mutual interference effects between the two stages are expected to be largest. A schematic illustration of the test matrix data points is presented in Figure 7 for $\Delta \quad \Delta \beta \quad 0$ and sample Schlieren images of the flow field during separation are presented in Figure 8. No test data was acquired when the upper stage was at nonzero sideslip angles. Additional details of AEDC tests are available in Ref. 5. 



Figure 8. Sample Schlieren images.

\section{CFD Solutions}

The power-on incremental database was generated using the OVERFLOW CFD code. ${ }^{6}$ The configuration used in the computations was the A106+ (also designated as A106p) configuration with all protuberances and 10 BDMs located at the mid location on the aft skirt. The A106+ configuration also provided definition of internal nozzle contour, the thrust cone, and J2-X thermal blanket as well as updated clocking of the BTMs.

The BDM and USM numbering is shown in Figure 9. The Patrick 63 atmospheric model $^{7}$ was used to estimate free stream static pressure, density, and temperature for input to CFD solution. To calculate the power-on incremental coefficients, pairs of CFD solutions, one for power-on and the other for power-off for identical flow conditions were generated. The majority of the CFD solutions were generated at nominal (TR6) separation conditions.

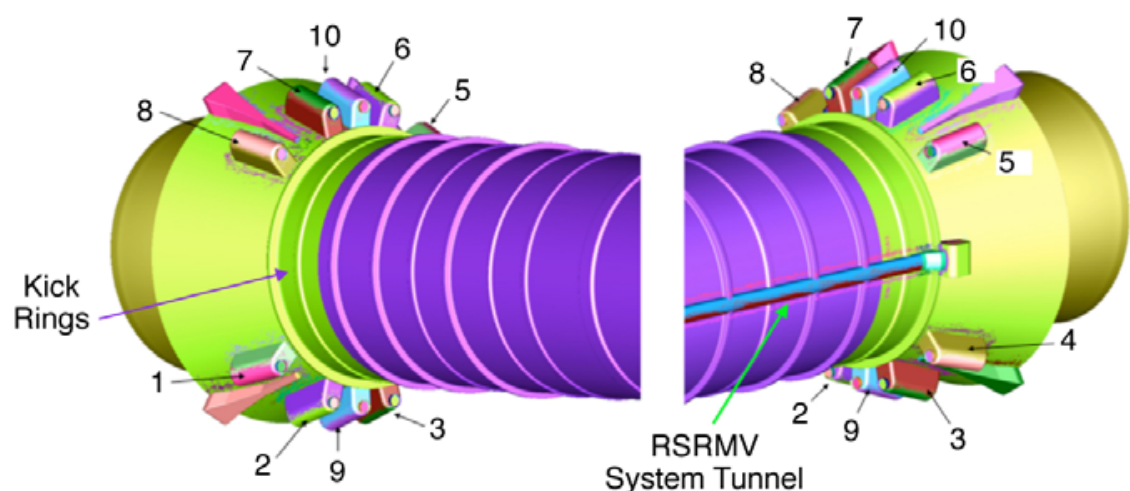

(a) BDM (view: from front to aft)

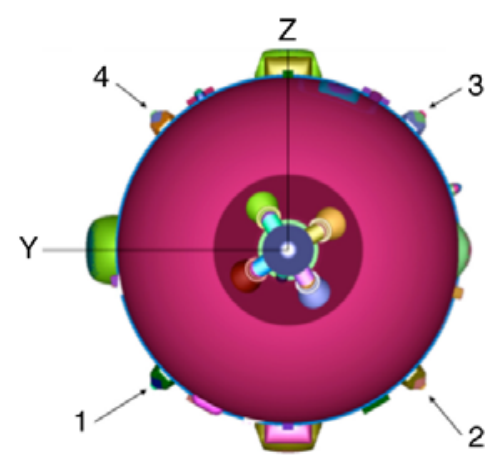

(b) USM (view: from front to aft).

Figure 9. BDM and USM nomenclature.

American Institute of Aeronautics and Astronautics 
The USM, BDM, RSRMV and J2-X plumes and their firing schedules and thrust profiles were modeled using GNC7 input data. A plot of the nominal thrust profiles is shown in Figure 10. The USM thrust varies very little during the $2.5 \mathrm{sec}$ duration of separation event. The BDM thrust reaches its peak value between 0 and 0.4 seconds, and then tails off rapidly. The RSRMV thrust tails off gradually. The J2-X thrust is essentially zero at the start of separation but slowly builds up as shown. The LAS, RoCS, and ReCS plumes were not modeled in CFD solutions. These time based nominal thrust profiles were tied to Xsep/D via TD7 nominal separation time history.

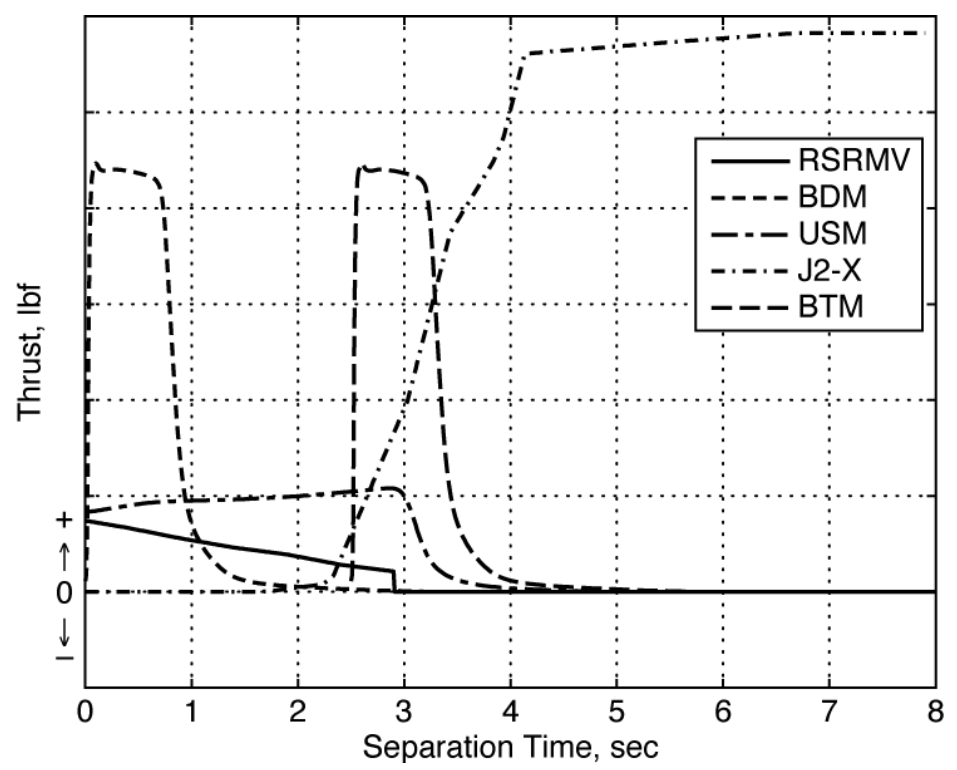

Figure 10: Total thrust time histories.

OVERFLOW is a structured grid Navier-Stokes flow solver ${ }^{8}$ using overset grids or zones to handle the complex geometry involved with the A106p configuration. The first and upper stage surface definitions for this configuration are shown in Figure 11. The overset grid system used for A106p is shown in Figure 12(a) and a close up of the region around the $\mathrm{J} 2-\mathrm{X}$ nozzle and the first stage cup is shown in

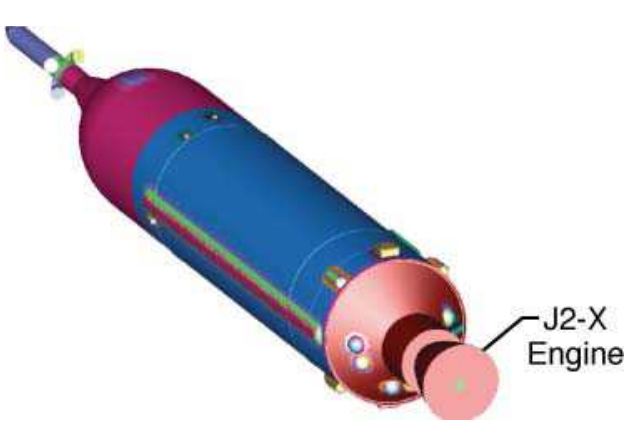

(a) Upper Stage.

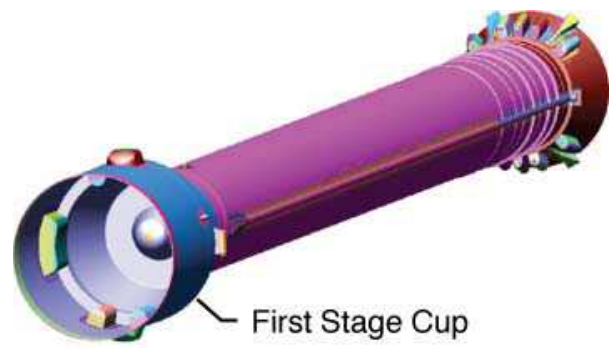

(b) First Stage.

Figure 11. Surface definitions used in OVERFLOW CFD computations.

Figure 12(b). A typical grid system for these computations consists of about 200 zones and a total of about 260 million grid points. To ensure that the CFD solutions are grid independent, overset grid best practices were followed. ${ }^{9}$ In addition to ensure that the physics of the plume effects applicable for stage separation aerodynamics are accurately modeled, plume validation studies were carried out as reported in Ref. 10. It was not possible to obtain experimental data for the plume effects with the A106p configuration to use for CFD code validation.

An estimated 35 million CPU hours on the Pleiades computer system at NASA Ames Research Center were needed for: 120 solutions for power-on (60 each for plume-on and plume-of), 26 for BDM-out and 16 for USM-out cases.

The flow field Mach and surface pressure contours at $\mathrm{Xsep} / \mathrm{D}=0.1$ for power-off (no
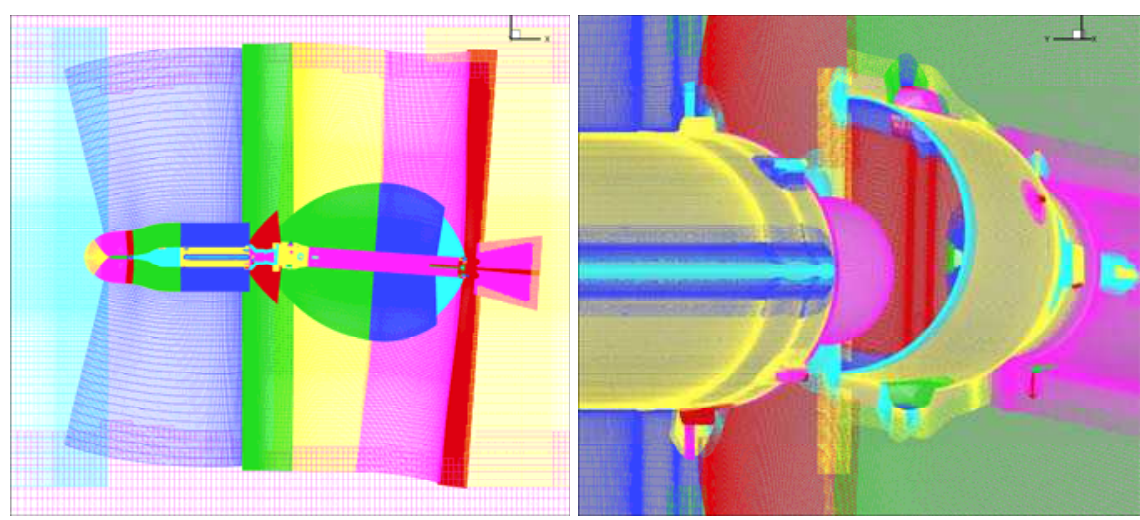

(a) A106 overset grid system. (b) J2-X nozzle and first stage cup area.

Figure 12. Overset grid system used in OVERFLOW CFD computations. 
plumes) and power-on (all plumes at nominal conditions) are shown in Figure 13. The flow field in the J2-X nozzle and first stage cup for Xsep/D $=0.6$ is shown in Figure 14. The flow field in the aft skirt region for BDM\# 10 failure is shown in Figure 15. Note that $\mathrm{Cp}$ (pressure coefficient) contours show surface pressure distribution. Complete details of CFD work are available in Ref. 8.

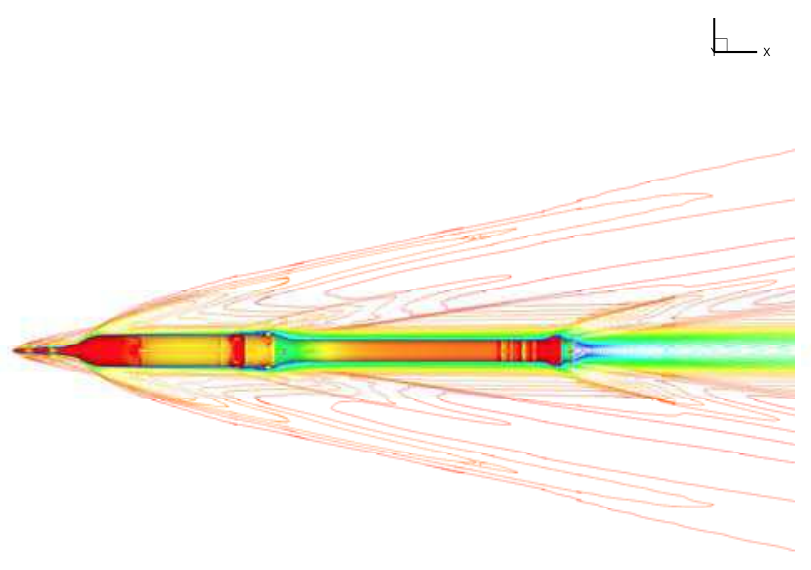

(a) plume-off.

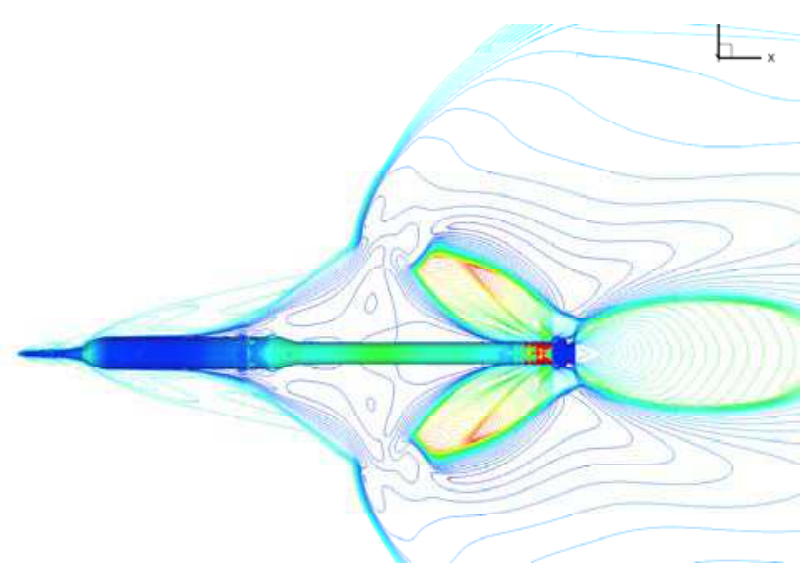

(b) plume-on.

Figure 13. Mach and surface pressure contours, $\alpha=0, \Delta \alpha=0, \Delta \beta=0, R \operatorname{sep} / \mathrm{D}=\mathbf{0}, \mathrm{Xsep} / \mathrm{D}=\mathbf{0 . 1}(\mathrm{Y}=\mathbf{0}$ plane $)$.

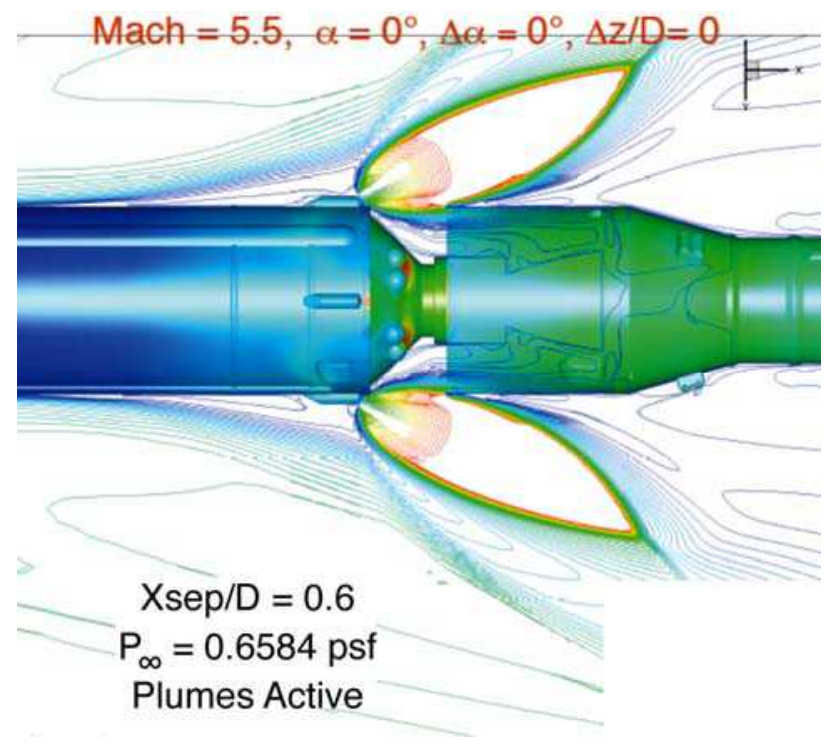

Figure 14. Mach and surface pressure contours around the $\mathrm{J} 2-\mathrm{X}$ and the first stage cup region, $\mathrm{M}=$ 5.5, Xsep/D $=0.6, \alpha=0, \Delta \alpha=0$ and Zsep/D $=0$.

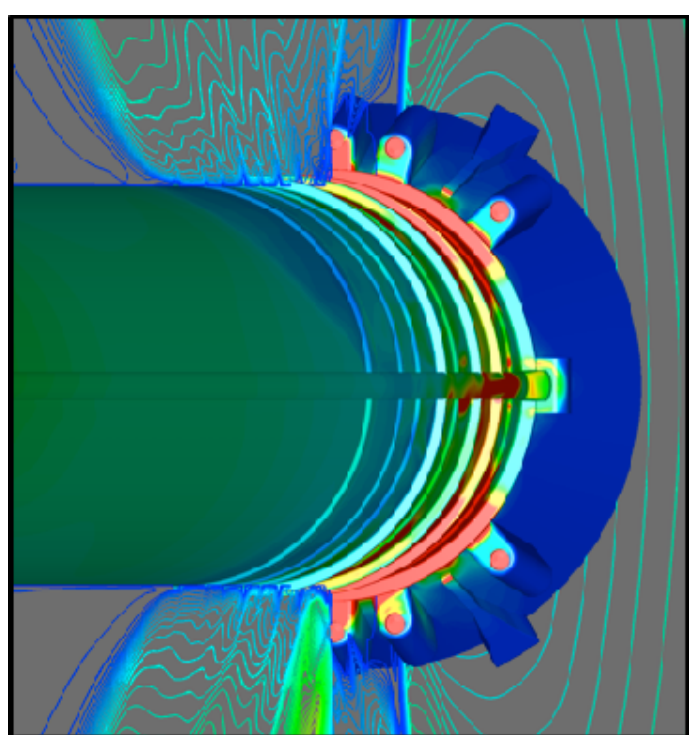

Figure 15. Mach and surface pressure contours in aft-skirt area for BDM\#10 failure case. 


\section{Database Development}

All the aerodynamic coefficients in the database are provided in the body axis system. The methods and procedures used for each database are discussed in the following:

\section{A. Isolated (Freestream) Database}

The AEDC test data on upper stage and first stage in isolation were used to develop this database. This database consists of six (6 DOF) aerodynamic coefficients $\left(\mathrm{C}_{\mathrm{N}}, \mathrm{C}_{\mathrm{A}}, \mathrm{C}_{\mathrm{Y}}, \mathrm{C}_{\mathrm{m}}, \mathrm{C}_{\mathrm{l}}, \mathrm{C}_{\mathrm{n}}\right)$ for both upper stage and first stage as functions of angle of attack and sideslip.

\section{B. Power-off Database}

The power-off database provides the mutual aerodynamic interference effects of the first stage and upper stage while in proximity during the stage separation event for plume-off conditions. The power-off database was developed using AEDC test data on A103 clean configuration (no protuberances). The A106 clean configuration is very close to the A103 clean configuration. In view of this, this database is assumed to be applicable for A106 configuration. However, there are some differences in protuberances between A103 and A106. It is assumed that the influence of these protuberances is negligible on the proximity aerodynamic coefficients.

The power-off incremental coefficients were calculated by subtracting the isolated (freestream) coefficients from the proximity coefficients for corresponding angle of attack/sideslip. The database consists of six force and moment increment coefficients $\left(\Delta \mathrm{C}_{\mathrm{N}}, \Delta \mathrm{C}_{\mathrm{A}}, \Delta \mathrm{C}_{\mathrm{Y}}, \Delta \mathrm{C}_{\mathrm{m}}, \Delta \mathrm{C}_{\mathrm{l}}, \Delta \mathrm{C}_{\mathrm{n}}\right)$ for both the first stage and the upper stage. This 6 DOF database has 6 independent variables $\mathrm{Xsep} / \mathrm{D}, \operatorname{Resp} / \mathrm{D}, \kappa, \alpha_{\mathrm{T}, \mathrm{US}}, \Delta \alpha$ and $\Delta \beta$. That is, each of the six power-off incremental coefficient of the upper stage and the first stage depend on these 6 independent variables.

The test data covers the following range of variables: Xsep/D $=0$ to 10 , Rsep/D $=0$ to 2.0 , upper stage angle of attack, $\alpha=0,5$ and $10 \mathrm{deg}$. Because the upper stage is axially symmetrical, $\alpha=\alpha_{\mathrm{T}, \mathrm{US}}$. For each of the three values of $\alpha$, the first stage relative angles of attack $(\Delta \alpha)$ were $0, \pm 5$ deg and relative sideslip $(\Delta \beta) 0, \pm 5 \mathrm{deg}$. That is, for each $\alpha$, there were 9 combinations of $\Delta \alpha$ and $\Delta \beta$, making it a total of 27 data sets. Since the test models were axially symmetrical (except for upper stage LAS nozzles), the upper stage can be assumed to be at total angles of attack of 0,5 and $10 \mathrm{deg}$. With this assumption, the power-off incremental coefficients when the upper stage is at combined angle of attack and sideslip (such that total alpha is below $10 \mathrm{deg}$ ) can be deduced using the available database. The detail procedure for these calculations is given in the A106 aerodynamic data book. ${ }^{11}$

The database was populated at selected break points in Xsep/D, Rsep/D and $\kappa$ using multi-dimensional linear interpolation. Even though the CTS rig was pre-programmed to take data at specified Xsep/D, Rsep/D and $\kappa$, the actual values of these variables slightly different. The TD7 dispersed trajectories indicate that around $1.5 \mathrm{sec}$ from separation initiation when Xsep/D is approximately 1.914, the first stage cup clears the J2-X nozzle. After 2.5 seconds when the two stages are about 4.25D apart, the tumble motors fire and the stage separation database discussed in this paper is no longer applicable. Hence, the power-off database was truncated at Xsep/D = 5.4 which was the next closest break point in the AEDC test matrix.

\section{Power-on Database}

This database accounts for plume interference effects. It has three parts: (i) all motors firing at their nominal thrust values, (ii) one BDM out, others firing nominally, and (iii) one USM out, others firing nominally. These three databases were generated using CFD solutions as discussed earlier. An approximate procedure for accounting for some or all BDMs firing at off-nominal thrust is presented in the A106 aerodynamic databook. ${ }^{11}$

\section{All-Plumes Nominal Firing Database}

The all plumes nominal firing database is an increment relative to the power-off database, that is freestream coefficients plus power-off increments. The pairs of OVERFLOW CFD solutions for power-on and power-off for identical flow conditions were used to calculate these increments. The power-off OVERFLOW solutions compared well with AEDC proximity test data to give confidence in the use of OVERFLOW for power-on computations. However, the power-on CFD solutions could not be validated because suitable test data are not available. Performing power-on stage separation tests was outside of the scope of this activity.

Due to resource limitations, only a limited number (60 each for power-off and power-on, total 120) of selected CFD runs were made. However, they were not adequate to develop a detailed 6 dimensional database. The TD7 dispersed separation trajectories indicated that the dispersions in $\alpha, \beta, \Delta \alpha, \Delta \beta, \mathrm{Rsep} / \mathrm{D}$ and $\kappa$ from their nominal separation values (all are close to zero) are small. Therefore, it was decided to develop a simple, one-dimensional model with Xsep/D as the only independent variable and include all variations due to the rest of the independent variables 
in uncertainty estimation. Thus, for a given $\mathrm{Xsep} / \mathrm{D}$, the data in the database is the mean value of available incremental coefficients for various $\alpha, \beta, \Delta \alpha, \Delta \beta$, and Rsep/D at that $\mathrm{Xsep} / \mathrm{D}$ and differences between this mean model and the actual CFD increments were used to estimate uncertainty.

All incremental coefficients other than axial force increments were very small. Therefore, they were set to zero for both the first stage and the upper stage and residuals were included in uncertainty. ${ }^{11}$

2. One BDM out Database

This database provides incremental coefficients for one BDM failure with respect to power-on (all plumes firing at nominal conditions) coefficients. A total of nine CFD solutions were available for BDM \#9, \#10, \#1, \#4 and \#5 out at various $\alpha$ and $\beta$ for Xsep/D = 0.1. The BDM out increments were computed by subtracting the BDM out coefficients from the corresponding power-on coefficients. The BDM out database includes effects of $\alpha$ and $\beta$. The first stage axial force and rolling moment increments coefficients are independent of which BDM has failed because of symmetry. All the upper stage incremental coefficients were set to zero because they were negligible. Additional details on the development of one BDM out database are available in A106 aerodynamic data book ${ }^{11}$.

3. One USM out Database

A total of 8 CFD solutions were available for USM \#2 and \#4 out at Xsep/D =0.1, 0.6, 1.0 and 2.0 and for $\alpha$ and $\beta$ values of 0 and 4 , with $\Delta \alpha=0$ and $\Delta \beta=0$. The data for USM \#1 and \#3 were generated assuming symmetry. Details of this procedure are discussed in A106 aerodynamic data book. ${ }^{11}$

\section{Database Implementation}

The total aerodynamic coefficients for the upper stage and the first stage are obtained by summing up the freestream coefficients, power-off increments, power-on increments and one BDM-out or USM-out increments if applicable. The freestream coefficients, power-off and power-on incremental coefficients are nondimensionalized by freestream dynamic pressure. However, the one BDM-out and one USM-out incremental coefficients are based on the thrust of that BDM or USM if it were firing at nominal conditions. The detail procedure for implementing the database for nominal and dispersed staging conditions is given in Ares I aerodynamic databook. ${ }^{1}$

\section{Discussion}

The isolated (freestream) coefficients of the upper stage and the first stage at Mach 5.5 are presented in Figures 16 and 17. Since the power-off stage separation database is too large, it is not possible to present data plots to cover the entire range of the 6 independent variables. Therefore, a few selected plots are presented to illustrate the trends and variations of power-off increments. The upper stage and first stage power-off incremental coefficients for $\mathrm{Rsep} / \mathrm{D}=0$ and $\alpha=\beta=\Delta \alpha=\Delta \beta=0$ are presented in Figures 18 and 19. For the upper stage, the axial force increments are small for small values of Xsep/D because just at separation the base pressure is almost zero and the axial force is close to the isolated value. At Mach 5.5, the base pressure on the isolated upper stage is also very small because in hypersonic flow, the base pressure varies approximately as $1 / \mathrm{M}^{2}$. Therefore, the incremental axial force coefficient is close to zero. As the two stages move apart, the base flow gets established, the base pressure starts rising slowly and the axial force increment eventually approaches zero. The situation is opposite for first stage. A near zero pressure (vacuum) in the gap area results in a very small axial force and a large negative increment as shown in Figure 19. This negative increment would approach zero as the two stages move apart and as the flow gets established in the gap and pressure rises. All the other incremental coefficients for first stage are zero for this case. Another sample result for the first stage for Rsep/D $=0.2, \alpha=0, \beta=0, \Delta \alpha=0.0$, and $\Delta \beta=0$ is presented in Figure 20. The axial force increment follows the same trend as in Figure 19. Due to radial offset ( $R s e p / D=0.2$ ), the normal force, pitching moment, side force and yawing moment increments start building up as shown. The normal force and pitching moment increments at $\kappa=0$ and 180 deg are equal and opposite because these are anti-symmetric about the horizontal plane $(\kappa=90 \mathrm{deg}$ and $270 \mathrm{deg}$ ). The side force/yawing moment increments are zero $\kappa=0$ and $180 \mathrm{deg}$, but have equal and opposite values $\kappa=90 \mathrm{deg}$ and $270 \mathrm{deg}$. These two coefficients are anti-symmetric about the vertical plane ( $\kappa=0$ and $180 \mathrm{deg})$. The rolling moment increments were very small and set to zero for this case.

The power-on axial force increments are shown in Figure 21 for upper stage and Figure 22 for first stage. These increments are larger than the corresponding power-off increments, particularly for the first stage. For $\mathrm{Xsep} / \mathrm{D}<0.5$, the impingement pressure on the RSRMV kick rings (Figure 9) due to BDM jets produces a thrust resulting in negative axial force increments. As Xsep/D increases, the pressurization of the first stage cup due to USM jets becomes significant and balances this thrust causing the incremental axial force approach zero. For Xsep/D > 2.5, the J2-X thrust starts building up and impingement of its plume on the first stage cup produces large axial force resulting in large positive increments as observed in Figure 22. 

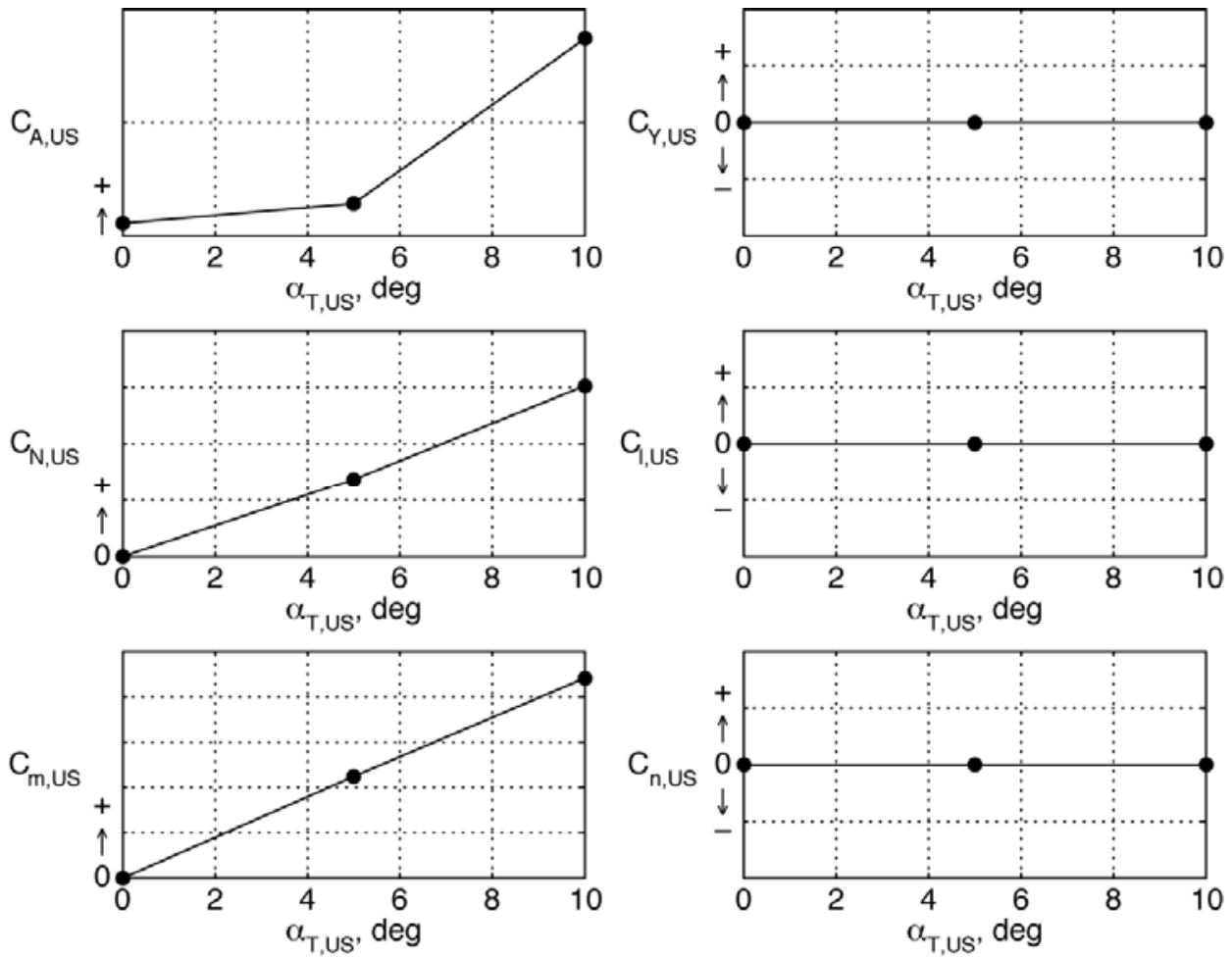

Figure 16. Upper stage freestream coefficients.
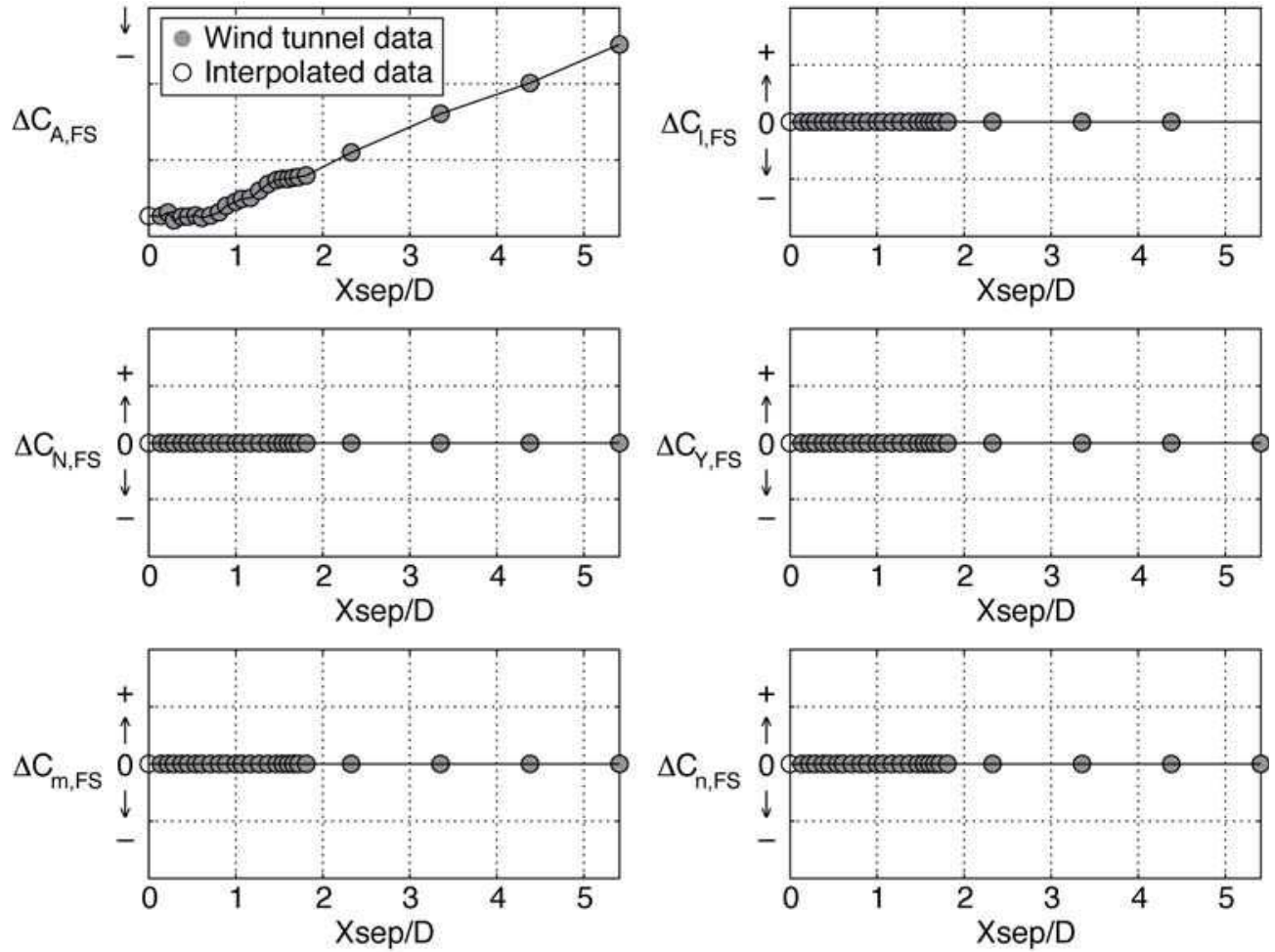

Figure 17. First-Stage freestream coefficients.

12

American Institute of Aeronautics and Astronautics 

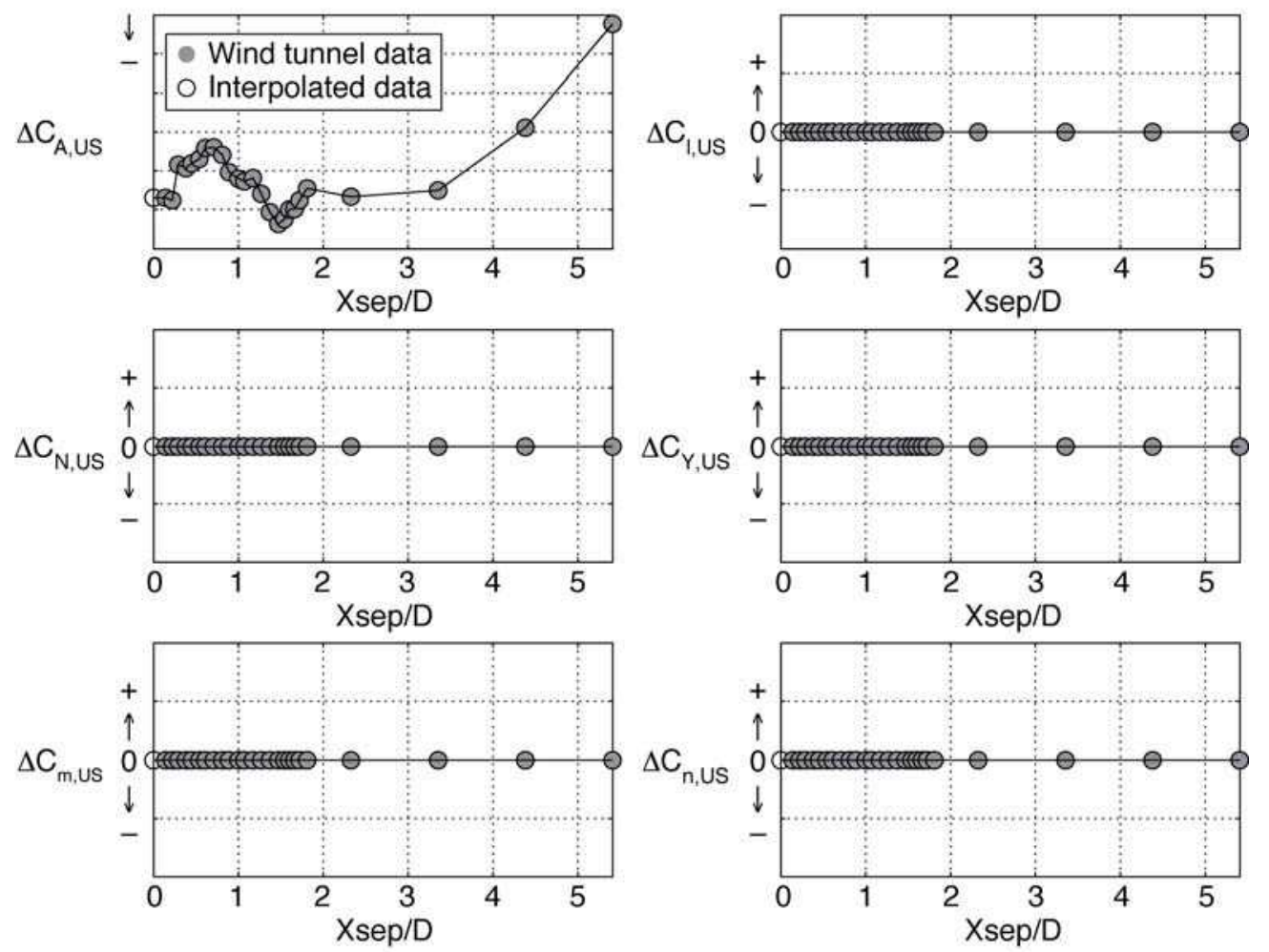

Figure 18. Power-off upper-stage incremental coefficients, $\alpha_{\mathrm{T}, \mathrm{US}}=\mathbf{0}, \Delta \alpha=0, \Delta \beta=0, \operatorname{Rsep} / \mathbf{D}=0$.
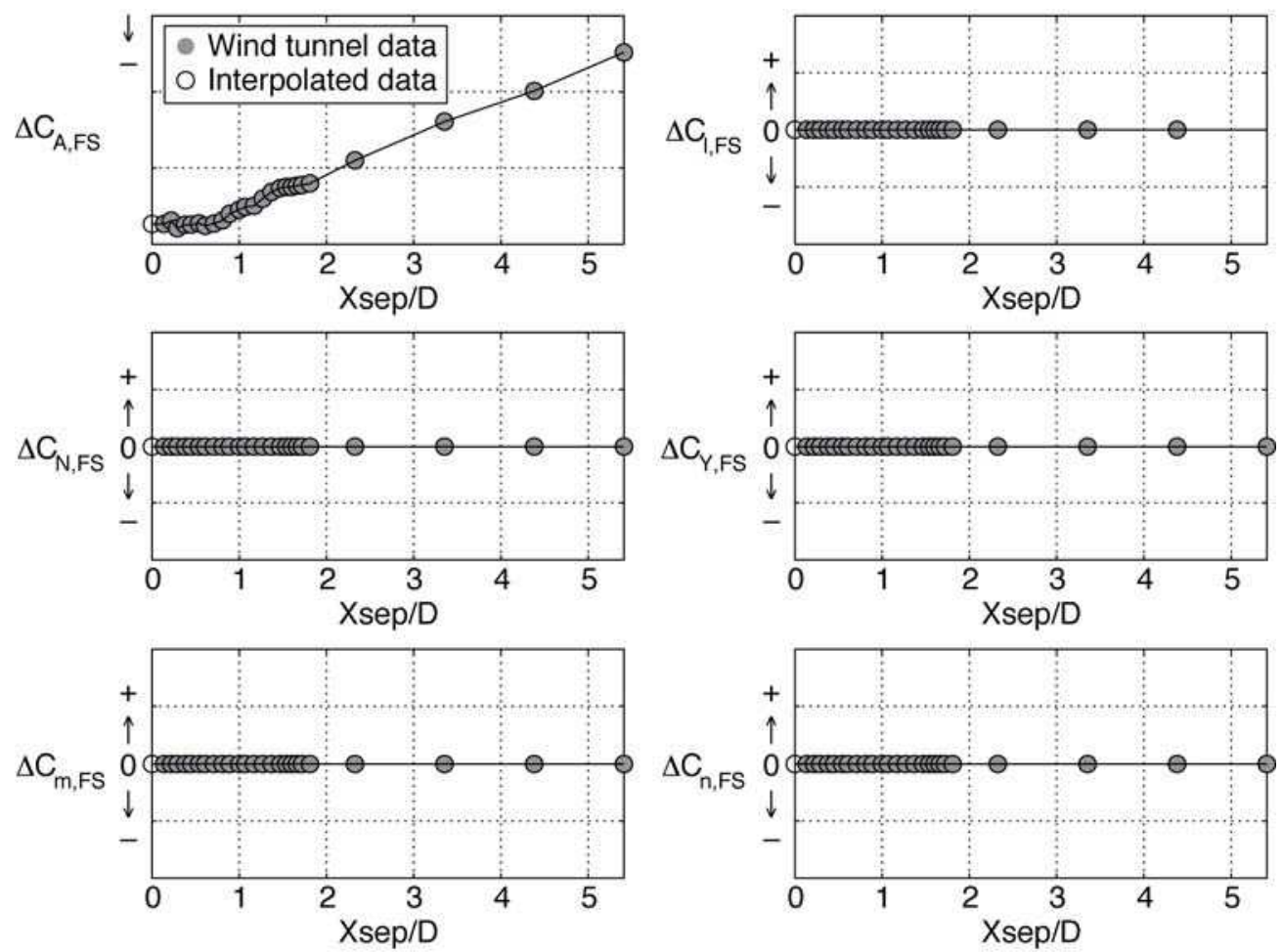

Figure 19. Power-off first-stage incremental coefficients. $\alpha_{T, U S}=0, \Delta \alpha=0, \Delta \beta=0, R \operatorname{Rep} / D=0$. 

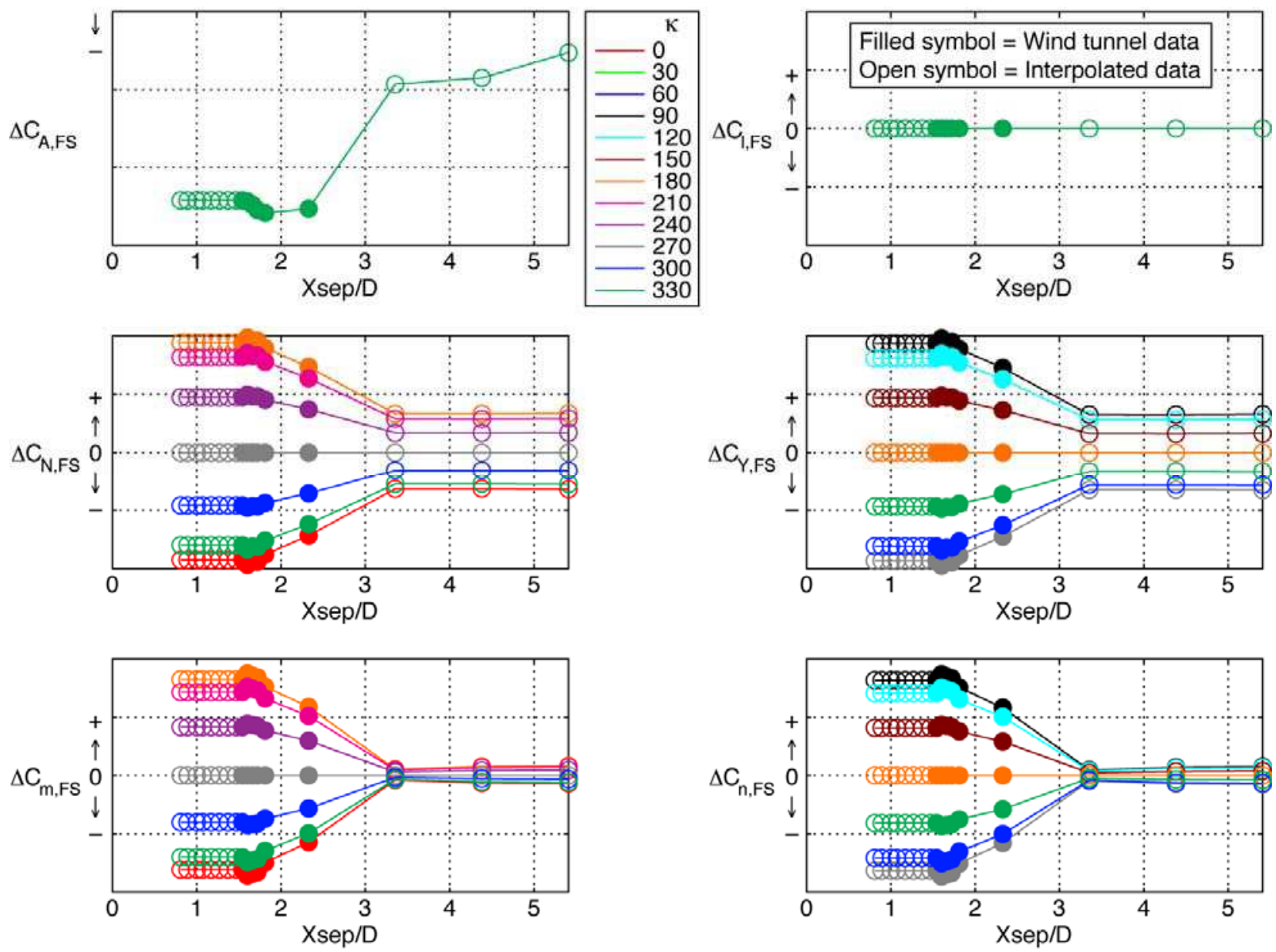

Figure 20. Power-off first-stage incremental coefficients, $\alpha_{T, U S}=0, \Delta \alpha=0, \Delta \beta=0, \operatorname{Rsep} / \mathbf{D}=0.2$.

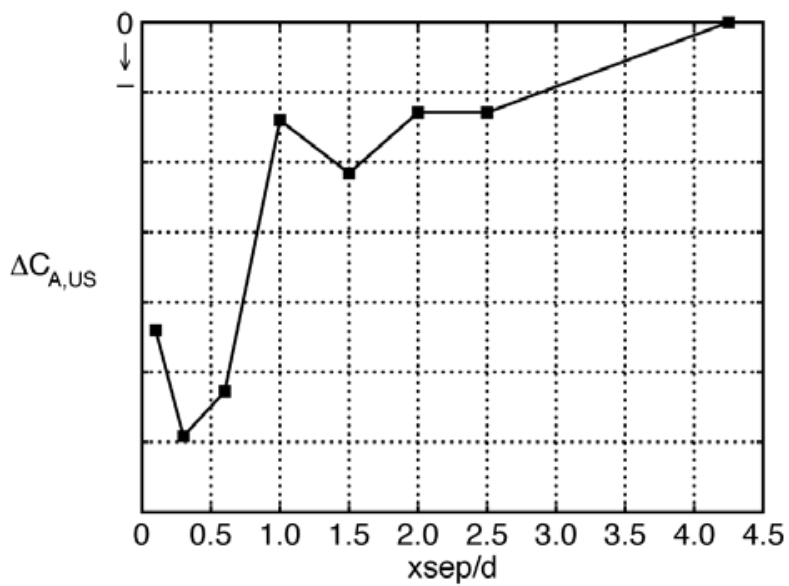

Figure 21. Power-on upper stage axial force increments. 
One BDM out force and moment increment coefficients (thrust based) are shown in Figure 23. It is observed that significant forces and moments result due pressure imbalance on the first stage, particularly in the aft skirt region. As an example for a BDM\#10 failure, the pressures on the bottom side where its counterpart BDM\#9 is firing are relatively higher and this pressure imbalance results in a large positive normal force and an associated pitching moment. Similarly, when BDM\#1 or \#5 fail, a large side force and associated yawing moment arise. It was observed that these normal/side forces and associated pitching/yawing moments overwhelm the power-on (all firing) incremental forces/moments. As a result, the critical test for safe separation happens to be the one BDM failure case because these large increments in forces and moment further reduce the clearance between the first stage cup and the J2-X nozzle as the first stage cup tries to clear the J2-X nozzle (Figure 5). This is the most critical phase of the Ares I mission. The GNC cycle 8 Monte Carlo simulations using this database will actually identify the critical BDM failure case.

One USM out force and moment increment coefficients (thrust based) are shown in Figure 24 for upper stage and Figure 25 for first stage. These incremental coefficients are very small compared to BDM-out increments and may have negligible effect on separation clearance.
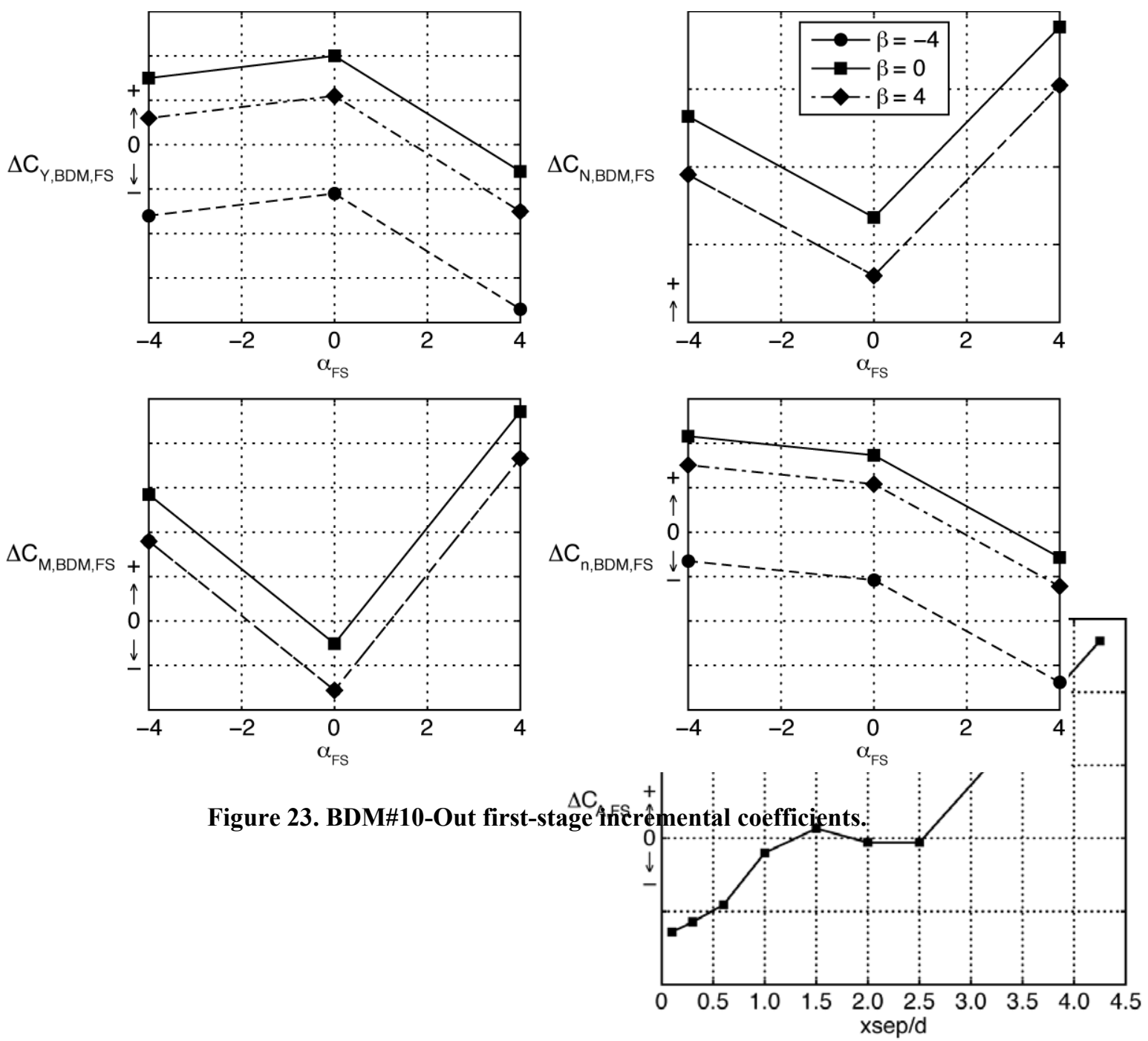

Figure 22. Power-on first stage axial force increments. 

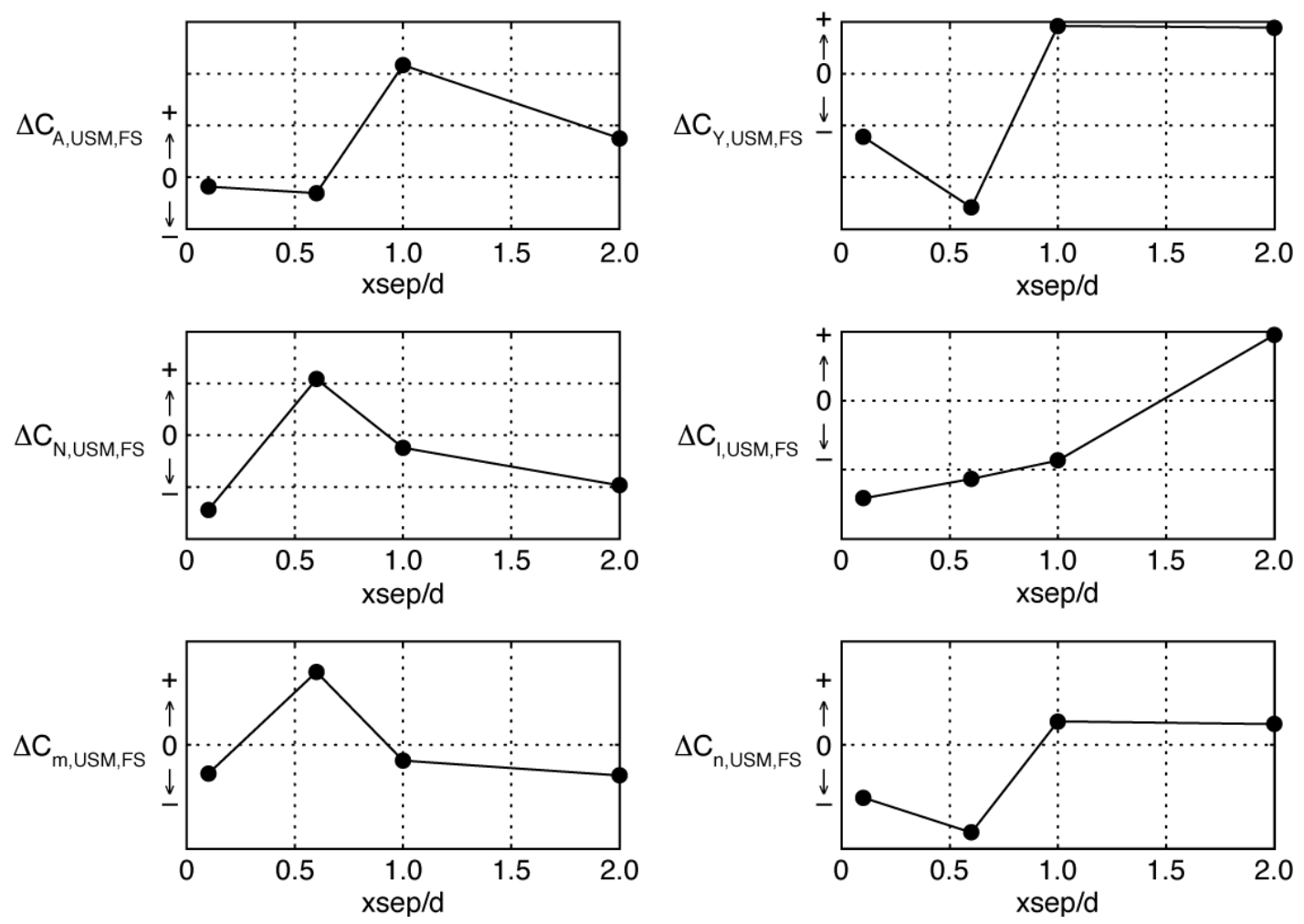

Figure 24. USM\#1-Out upper-stage incremental coefficients.
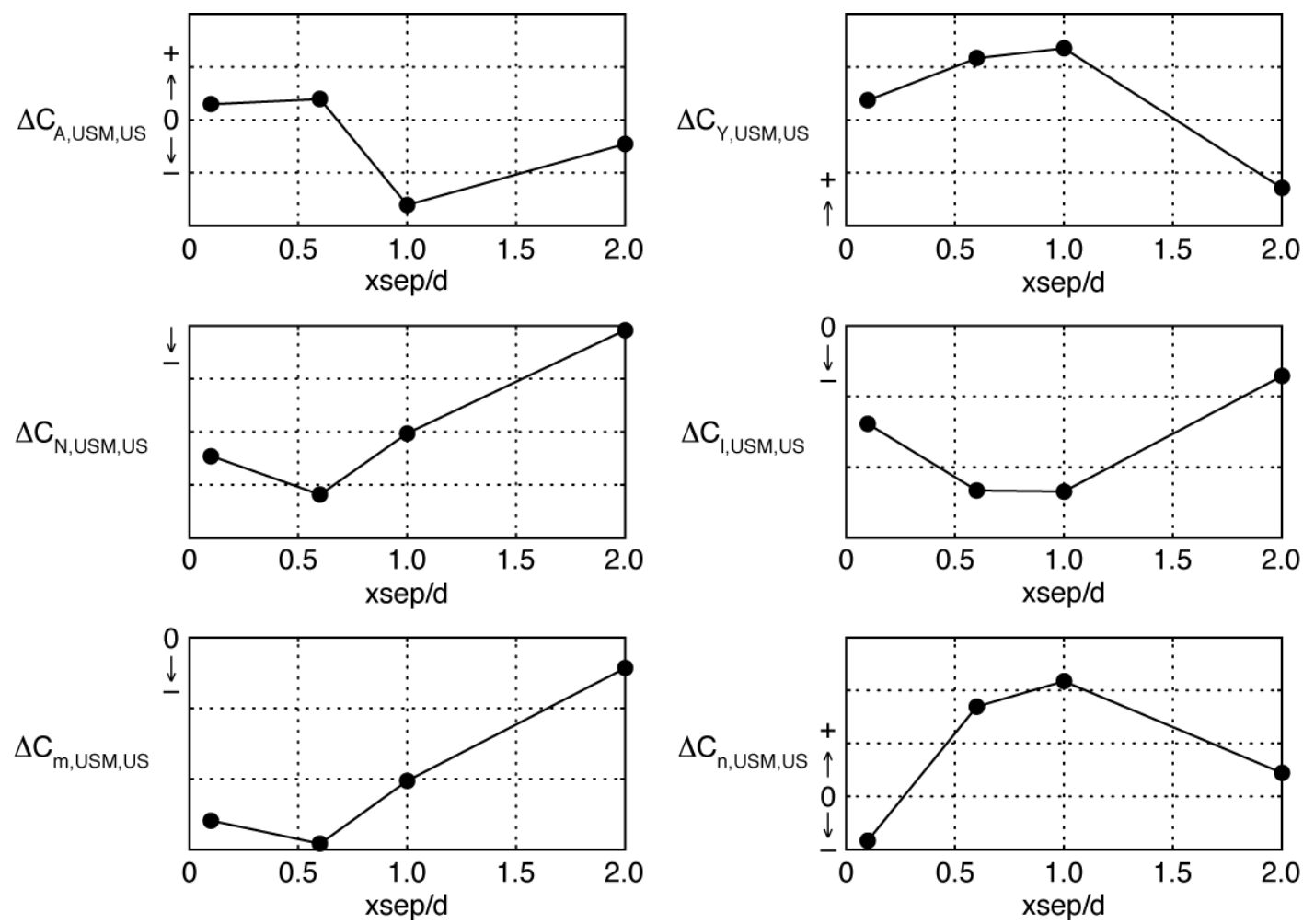

Figure 25. USM\#1 out first stage incremental coefficients.

American Institute of Aeronautics and Astronautics 


\section{Concluding Remarks}

The proximity aerodynamics during Ares I A106 crew launch vehicle stage separation is complex and challenging due to the presence of USM, BDM and J2-X plumes causing complex flow interactions in the upper stage base area and the first stage open cup region. It is a challenging task to design and fabricate powered test models due to size limitations (typically 1\% scale models) and simulate all the plumes and obtain reliable test data for database development. Modern CFD tools offer a viable option but are expensive and difficult to validate without suitable test data. Conducting power-on tests was beyond the scope of this activity. In view of this, the approach taken was to perform power-off stage separation tests at AEDC VKF Tunnel A and use the OVERFLOW CFD code for estimating power-on increments.

The stage separation database consists of three components: freestream coefficients, power-off increments and power-on increments. The database also consists of two additional components, one BDM out and one USM out incremental coefficients. The freestream and power-off incremental database were developed using stage separation test data. All the power-on incremental coefficients were estimated using OVERFLOW CFD solutions. It was observed that the power-on effects overwhelm the power-off effects.

An estimated total of 130 air-on occupancy hours at AEDC VKF Tunnel A were needed for obtaining the requisite power-off stage separation test data. The limited power-on OVERFLOW CFD computations used in power-on database development including BDM and USM out cases took about 35 million CPU hours on the Pleiades computer system at NASA Ames Research Center. In spite of using such a large number of CPU hours, it was not possible to develop a suitable multi-dimensional power-on database. Simplified models were developed for the power-on database. All the parameters not modeled in power-on database were included in developing uncertainty. Since power-on OVERFLOW CFD solutions were not validated, uncertainties assume large values. Estimation of uncertainty was not discussed in this paper but are available in A106 aerodynamic data book. ${ }^{11}$

\section{Acknowledgment}

Dr. Khaled S. Abdol-Hamid, Dr. Robert M. Hall, Dr. Michael J. Hemsch and William G. Tomek are acknowledged for their help and assistance throughout the course of this activity.

\section{References}

${ }^{1}$ Huebner, L. D.; Haynes, D. A.; Taylor, T. L.; Hall, R. M.; Pamadi, B.N.; and Seaford, M. C.: "Status, Plans, and Initial Results for Ares I Crew Launch Vehicle Aerodynamics," Journal of British Interplanetary Society (UK), Vol. 61, 2008.

${ }^{2}$ Pamadi, B.N., Pei, J., Covell, P.F, Favaregh, N.M, Gumbert, C.R., and Hanke J.L,: “Aerodynamic Analyses and Database Development for Lift-OFF, Transition and First Stage Ascent of the Ares I A106 Vehicle," 49th AIAA Aerospace Sciences Meeting, Orlando, FL, January 2011. 1967.

${ }^{3}$ Nunley, B.W.: "Static Aerodynamic Characteristics of the Apollo-Saturn IB Vehicle," NASA TM X-53657, September 25,

${ }^{4}$ Anonymous, “Ares I System Requirements Document," Constellation Project Document, CxP 72034), Stage Separation Requirement R.CLV.95.

${ }^{5}$ Pinier, J. T. and Niskey, C. J.: "Ares I and Ares I-X Stage Separation Aerodynamic Testing”, 49th AIAA Aerospace Sciences Meeting, Orlando, FL, January 2011.

${ }^{6}$ R.H. Nichols, R.W. Tramel, and P.G. Buning, "Solver and Turbulence Model Upgrades to OVERFLOW 2 for Unsteady and High-Speed Applications," AIAA-2006-2824, AIAA 36th Fluid Dynamics Conference, San Francisco, CA, June 2006. 1961.

${ }^{7}$ Smith, O. E., A Reference Atmosphere for Patrick Air Force Base, Florida, Annual, NASA Technical Note D-595, March

${ }^{8}$ Klopfer, G.H., Onufer., J.T, Pandya, S.A., Chan, W.M., Kless, J.E, and Lee, H.C.: "OVERFLOW Aerodynamic Predictions of the Ares 1 A106p Stage Separation Process with Viscous Plume Effects," NASA TM to be published in February 2011.

${ }^{9}$ Chan, W. M., Gomez, R. J., Rogers, S. E., and Buning, P. G., "Best Practices in Overset Grid Generation," AIAA Paper 2002-3191, 2002.

${ }^{10}$ J. E. Kless, H.C. Lee, G. H. Klopfer, J. T. Onufer,: "Validation of OVERFLOW for Computing Plume Effects during the Ares 1 Stage Separation Process,” 49th AIAA Aerospace Sciences Meeting, Orlando, FL, January 2011.

${ }^{11}$ Constellation Program Ares I Aerodynamic Data Book. CxP 72214, December 2010. 